\title{
Parents' Experiences with an Individualized Intervention Designed to Strengthen the Family-School Partnership: The Parents in Partnership with Educators (PIPE) Program
}

\author{
Courtney Cadieux, Claire Crooks, and Colin King \\ Western University
}

\begin{abstract}
Mental health challenges are common among children, and can interfere with learning and adjustment to school. Although early intervention is crucial and the family-school partnership plays an integral role in the development and implementation of individual education plans (IEPs), there are few supports to assist families in navigating this partnership. This study describes the experiences of parents who participated in the Parents in Partnership with Educators (PIPE) program, an individualized intervention for families who are struggling to communicate and problemsolve with schools around the mental health needs of their children. File review and semi-structured interviews were conducted for ten families. Results indicated that the program gave parents unconditional support and guidance, as well as new skills to help them communicate their perspective in a meaningful way. Parents reported feeling empowered, informed, and prepared to advocate for their children.
\end{abstract}

Parental involvement is an important aspect of youth education and can be defined as "the participation of parents in regular, two-way, and meaningful communication involving student academic learning and other school activities" (Anfara \& Mertens, 2008, p. 58). Parental involvement with the school is linked to positive outcomes, including both academic (Epstein \& Sheldon, 2002) and behavioural (Jarmuz-Smith, 2011). For instance, research has identified positive relationships between parental involvement and grade-point average, lower drop-out rates, and school engagement (Hoover-Dempsey et al., 2005). Specifically, for children with disabilities, an efficacious 
partnership between families and schools can make a considerable difference for students' success (Mautone, Marcelle, Tresco, \& Power, 2015).

Students may require personalized and tailored school supports guided by an individual education plan (IEP). The IEP is a contract between the parents, school, and students over 16 years old that "identifies the student's specific learning expectations and outlines how the school will address these expectations through appropriate accommodations, program modifications and/or alternative programs as well as specific instructional and assessment strategies" (Ontario Ministry of Education, 2017, para. 2). The expectation is that, with these accommodations or modifications, students will be able to achieve the learning outcomes as outlined within the Ontario curriculum.

Parental involvement in the development of a student's IEP is both crucial and legally mandated in Ontario (Ontario Ministry of Education, 2004, p. 13); however, research suggests that parent participation during IEP meetings is relatively low compared to that of teachers and administrators (Martin et al., 2006). These documents must be updated at the beginning of each reporting period; however, IEPs are "living documents" and can be updated and/or changed at any time (Ontario Ministry of Education, 2004, p. 48). Unfortunately, parents are often limited to signing paperwork, rather than actively participating in an ongoing collaboration between the home and school or in the decisionmaking process (Fish, 2008). This discrepancy between the law to involve parents and the reality of their involvement is of importance given the body of research linking parental involvement to positive student outcomes (Castro et al., 2015; Jeynes, 2005; Ma, Shen, Krenn, Hu, \& Yuan, 2016). Not only is improving the quantity and quality of parental involvement with the school central to the success of the student, it has been shown that poor parent-school relationships are predictive of high rates of litigation (Burke \& Goldman, 2015), which are costly for the schoolboard. Additionally, most teacher preparation programs do not provide specific training on how to establish partnerships with parents (Jivanjee, Kruzich, Friesen, \& Robinson, 2007), and parent training programs on how to communicate with the school are rare (Murray, Ackerman-Spain, Williams, \& Ryley, 2011). Therefore, it is necessary that efforts are put into place to help parents and schools come together to develop solutions that will benefit the student.

This paper explores the experiences of 10 adults who have participated in an individualized communications intervention for parents of children who are struggling to communicate with the school around the mental health needs of their children. The Parents in Partnership with Educators (PIPE) program was developed to help parents foster positive school partnerships by providing guidance, organizational tools, and hands-on support for parents preparing for a school meeting. This program was locally developed by the director of a non-profit organization and has been piloted in one city in southwestern Ontario. The purpose of this study was to explore why parents enrol in the program and what they gain from their involvement, as well as to gain a deeper understanding of the factors that help parents resolve conflicts with their child's school. To address this purpose, we reviewed families' PIPE files and conducted semi-structured interviews after they had completed the program. This study was conducted within a community-based partnership between the director of the PIPE program and the authors and was funded by an internal grant at a Canadian university. 


\section{Conceptual Framework}

This paper draws on the Hoover-Dempsey and Sandler model of the parental involvement process (Green, Walker, Hoover-Dempsey, \& Sandler, 2007). This theory suggests that encouraging parents' confidence, understanding, and skills through initiatives such as PIPE plays an important role in achieving meaningful communication between schools and families. The model is valuable for its emphasis on parental role construction, or parents' own beliefs about their role as a parent in the education system (Auerbach, 2007). This model suggests that parental role construction is the most salient predictor of parental involvement and that motivation for involvement comes from three sources: (a) parent motivation, (b) school invitations, and (c) family context. Parent motivation includes parental role construction as well as parents' beliefs about their selfefficacy in relation to their child's education. These beliefs are influenced by several factors, such as family, co-workers, gender, socio-economic status, and cultural norms (Gonzalez, Borders, Hines, Villalba, \& Henderson, 2013). School invitations include general perceptions of a welcoming school environment, specific invitations from teachers, and specific invitations from the child. Family context variables are often considered barriers to involvement, such as parents' knowledge and skills as well as other demands on their time and energy (Gonzalez et al., 2013). Research on the model's predictive ability suggests that it can be applied to families in diverse circumstances (Green et al., 2007; Gonzalez et al., 2013; Chrispeels \& Rivero, 2001).

\section{Past Literature}

Research has identified a number of barriers hindering successful parent-school partnerships with regard to the development and implementation of IEPs, such as scheduling conflicts, parental lack of knowledge about school policies and/or academic terminology, and perceived inequality on the IEP team (Jivanjee et al., 2007). Poverty, educational attainment, and immigrant status also influence the degree of parental involvement (Chrispeels \& Rivero, 2001). Specifically, families of low socio-economic status and with lower levels of education have been found to participate less during IEP meetings (Jones \& Gansle, 2010). These parents may be less familiar with the terminology and/or feel more intimidated by the process compared to parents of higher socio-economic status or who have more years of education (Jones \& Gansle, 2010).

Results from a qualitative study on the IEP process for 20 parents revealed that many of them felt disregarded as a member of the team (Zeitlin \& Curcic, 2014). The IEP process produced strong, negative emotions for parents, many of whom used words such as "frustrated" and "overwhelmed" to describe the process. Another theme that emerged was the imbalance of knowledge, power, and authority among members of the IEP team. Some parents felt that they needed to become experts on their child's condition to be taken seriously. Lastly, parents struggled with the length of the IEP document and with its language, and they expressed concerns about the value of the IEP itself.

Research on interventions to improve parent involvement in this capacity is scarce; however, Goldman and Burke (2017) conducted a systematic review and meta-analysis to summarize the current literature on interventions to increase parental involvement for parents of school-aged students with disabilities who required an IEP. The two most 
recent studies included in the descriptive synthesis were by Jones and Gansle (2010) and Hirsch (2004). Jones and Gansle (2010) investigated the impact of a pre-IEP meeting mini-conference aimed at promoting parent involvement and the impact of parent education level on perceptions and observations of parent participation. Participants in the study included 14 special education teachers, 12 administrators, and 41 parents, the latter randomly assigned to the control condition $(n=20)$ or the experimental condition $(n=21)$. In the experimental condition, teachers conducted a mini-conference with the parents within seven days prior to the IEP meeting. In the control condition, teachers prepared for the IEP meeting as usual. Results revealed that teachers reported significantly more participation among parents from the experimental group compared to the control group. However, there were no significant differences between the two conditions for number of comments per minute made by parents, parent-rated perceptions of involvement, or administrator perceptions of involvement. The mini-conference between the teacher and parent did not improve parental attitudes, suggesting a need to develop and test other methods to increase parental participation.

Hirsch (2004) evaluated the use of an informational handout and one-on-one training for parents of children being assessed for a specific learning disability. Participants in the study included 45 parents who were randomly assigned to one of three groups. The training group received a package with information about specific learning disability and IEPs, and reviewed this information with the researcher prior to the school meeting. The attention group received information about child development and reviewed this information with the researcher prior to the school meeting. The control group received no information. Results revealed that observed and self-rated participation were significantly higher for parents in the training group compared to the attention and control group, and parents in the training group were significantly more knowledgeable following the training. Hence, providing explicit information about the child's condition and the IEP process may be an important strategy for improving parental involvement.

Overall, findings from the meta-analysis by Goldman \& Burke (2017) indicated that the interventions conducted to date did not effectively improve parental involvement during IEP meetings. Solely providing knowledge may be insufficient, as this only addresses a subset of the barriers faced by parents with regard to effective parent-school communication. It is clear that parental interventions aimed at improving communication among stakeholders are lacking, and programs that have been shown to be effective often target a specific population of students (Azad, Marcus, Sheridan, \& Mandell, 2018).

A recently developed program known as Partners in School is a parent-teacher consultation model for children with autism spectrum disorder (ASD; Azad et al., 2018). Similar to the program highlighted in the current study, the program employs a problemsolving model where parents and teachers work with a consultant to achieve a specified goal (Azad et al., 2018). Although similar to PIPE in some ways, PIPE was not based on this program. In this case, the goal is to work with an ASD specialist to increase the use of evidence-based practices for ASD in the home and at school. Partners in School is based on conjoint behavioural consultation (CBC; Sheridan, Kratochwill, \& Bergan, 1996), a framework in which parents, teachers, and a consultant participate in joint discussions to reach a solution for a child's academic or interpersonal problems (Sheridan, Eagle, \& Doll, 2006). A preliminary evaluation of this program assessed 
changes in child outcomes and found that teachers and parents reported perceived improvements in child outcomes, such as hyperactivity, following the program (Azad et al., 2018). The PIPE program does not involve the teachers in the actual intervention; rather, the goal is to build capacity for effective parent engagement during school meetings. Program such as Partners in School may be best suited for parents whose relationship with the school is not presently strained because these programs require immediate and ongoing collaboration between the parents and teacher. The PIPE program is unique because the goal is to bring parents back to the table and encourage their capacity as informed advocates for their children after a relationship has become problematic. Therefore, the PIPE program may serve as a first step toward involvement in a CBC-type program or further intervention.

\section{Methods}

Qualitative research methods were employed to examine parents' experiences with the PIPE program. This investigation was conducted within a community-based partnership with the director of the PIPE program from January 2018 through October 2018. All study materials and procedures were approved by the university's Non-Medical Research Ethics Board. Ten parents from southwestern Ontario, Canada, who had completed the PIPE program were contacted, two of whom agreed to participate but failed to schedule an interview with the researcher after multiple follow-up calls. Eight telephone interviews were conducted with parents who provided informed consent. A semi-structured interview was chosen because the structure is appropriate for investigating complex experiences, and it allows the researcher to clarify answers (Louise Barriball \& While, 1994). Additionally, the use of an interview guide is appropriate for participants with diverse backgrounds and circumstances (Louise Barriball \& While, 1994). Interview protocol included asking participants about how they discovered the PIPE program, what they took from their participation, whether there was anything negative about their experience, and how the program, if at all, made a continued impact on their communication with the school. Interviews took between 7 and 30 minutes to complete and were audio recorded and transcribed verbatim.

For each family that went through the PIPE program, the program representative recorded detailed notes at each meeting and put together a file outlining all documented information. A file review was conducted of the ten families (collectively including 16 children) who completed the PIPE program. This involved reviewing all intake assessments and field notes recorded by the program representative; including information such as family history, meeting dates, and meeting attendees. Identifying information was removed from files and transcripts, which were assigned a numeric code to preserve anonymity.

\section{Intervention}

The PIPE program is a consulting program that aims to strengthen the parent-school relationships by helping families work collaboratively with school personnel (e.g., teacher, principal, school psychologist). The program was developed by a non-profit organization called M.I. Understanding. M.I. Understanding (which stands for Mental Illness Understanding) is not a mental health organization; rather, it is a community of 
support aiming to encourage conversations about mental health among children and families. M.I. Understanding provides videos and community exhibits on topics such as anxiety, gender identify, help-seeking, exercise, and picky eating, among others. After meeting and connecting with families at the community exhibits, the director of M.I. Understanding recognized a need for families whose communication with the school had become problematic. The PIPE program was originally developed as a result of these conversations and has evolved into the current program over several years.

The goal of the PIPE program is to help parents become positive advocates for their child by widening their understanding of their own and the school's expectations and by building their confidence as knowledgeable and important members of the school team. The intervention involves four steps over a short period of time: (a) an information gathering session focused on identifying the core problems, conflicts, and barriers between family and school personnel; (b) a skills-based session to review a structured binder compiled by the program representative with all of the materials related to the child's education and care, and to practise communication skills; (c) a school-based meeting where the PIPE representative attends with the parent; and (d) a follow-up session with the representative to discuss next steps. During the first meeting, the parent shares their story with the program representative and the representative records any pertinent information. The representative asks the parent to request their child's Ontario Student Record (OSR), IEP, and any other relevant documents prior to their next meeting. The representative compiles a binder consisting of the relevant documents together with pre-meeting worksheets, which help parents prepare their objectives in advance of a school meeting. At the next meeting, the representative reviews the binder with parents and encourages them to practise vocalizing their concerns and questions out loud. The representative attends a school meeting alongside the parent at their discretion. Depending on the family, the program representative's role at the meeting ranges from simply taking notes to actively contributing to discussion.

\section{Data Analysis}

File review. Descriptive statistics from the intake questionnaires were used to summarize participant demographics. The field notes were analyzed using a pre-set codebook consisting of ten child categories (e.g., child age and gender) and nine parent categories (e.g., parent gender and number of children on IEPs). Each category was subsequently coded into categorical variables and input into SPSS statistical software (see Table 1).

Semi-structured interviews. The interview data were analyzed using a coding process as described by Erlingsson \& Brysiewicz (2017). Content analysis was employed, as this process allows for the identification of central themes that emerge from the raw data (Patton, 2002) and thus provides a deeper understanding of the participants' individual and shared experiences. The first step was to read the transcripts to get a general sense of what the participants were talking about. Meaning units (i.e., short excerpts from the text that illustrate singular ideas) were then extracted from the participant transcripts, and were given codes that succinctly described the meaning unit. Codes were assessed to determine which belong together, and were sorted into categories. Examples of categories included Emotional Support and Organization Skills. As 
suggested by Erlingsson and Brysiewicz (2017), codes were re-evaluated for overlap between categories and were rearranged as necessary. This iterative process resulted in several categories positioned around three overarching themes.

\section{Interview Participants}

All study participants were female $(N=8)$ and had a maximum of four children concurrently on IEPs $(M=1.75, S D=1.09)$. Children ranged from 4 to 13 years old $(64.3 \%$ male, $35.7 \%$ female; $M=8.91, S D=3.26)$. Two parents identified as immigrants, one of whom had been in Canada for one year. All protocols were approved by the university research ethics board.

\section{Table 1}

\section{Frequencies of Health-, School-, and Family-Related Concerns at the PIPE Program Intake Meeting}

\begin{tabular}{llr}
\hline Type of Concern & Official or Possible Diagnosis & Percent (\%) \\
\hline Health concern & & \\
& Speech and language delay diagnosis & 18.75 \\
& Possible speech and language delay* & 6.25 \\
& Anxiety diagnosis & 31.25 \\
& Possible anxiety* & 6.25 \\
& Oppositional defiant disorder diagnosis & 12.50 \\
& Attention-deficit/hyperactivity disorder diagnosis & 18.75 \\
& Possible sensory issues* & 18.75 \\
& Possible fine motor skill issues* & 6.25 \\
& Sleep disorder diagnosis & 6.25 \\
& Possible sleep disorder* & 12.50 \\
Behavioural concern & Learning disability diagnosis & 6.25 \\
& & \\
& Self-regulation (incl. aggression) & 18.75 \\
School concern & Attention & 12.50 \\
& & \\
Family concern & School refusal & 12.50 \\
& Peer victimization & 25.00 \\
\hline
\end{tabular}

Note: $N=16$. Most children presented with multiple concerns $(M=2.50, S D=1.30)$ ${ }^{*}$ Details of an official diagnosis were not provided.

\section{Results}

\section{File Review}

Participants discovered the program through several sources (i.e., Facebook, school referral, word of mouth, university conference). The problems that led parents to seeking out the PIPE program included a short-term misunderstanding or disagreement with the 
school surrounding the child's needs (37.5\%), a long-term dispute with the school $(12.5 \%)$, a poor relationship with the current teacher $(18.75 \%)$, concerns surrounding school transfers $(18.75 \%)$, or unknown $(12.5 \%)$. Refer to Table 1 for a summary of the children's presenting concerns at the intake meeting.

In nearly all cases (90\%), a formal intake meeting took place between the parent and the program representative. An organized binder including all information related to the child's school history (e.g., IEP, OSR) and several blank worksheets were compiled for $90 \%$ of parents. The program facilitator attended a school meeting with $80 \%$ of parent participants, and follow-up meetings were not recorded in the files; however, interview data revealed that all parents participated in a follow-up meeting or phone call. It is important to note that these cases include the inaugural families who were involved in PIPE when a systematic intake assessment or tracking procedure had not been established, which accounts for some of the variability in the process.

\section{Impacts of Participating in the PIPE Program}

Analysis and interpretation of the data generated three overarching themes including: (a) Having someone "on your team," (b) Learning and honing new skills, and (c) Parents' role as advocates (see Table 2). Exemplar quotations were identified during data analysis and have been included in the following section. Each quotation includes the participant ID.

Table 2

Impacts of Participating in the PIPE Program

\begin{tabular}{|c|c|c|}
\hline Overarching Themes & Secondary Themes & Exemplar Quote \\
\hline $\begin{array}{l}\text { Having someone "on } \\
\text { your team" }\end{array}$ & $\begin{array}{l}\text { - Personalized support } \\
\text { - Willingness and openness to } \\
\text { attend school meetings } \\
\text { - Guidance in the form of } \\
\text { resources }\end{array}$ & $\begin{array}{l}\text { It was just a huge relief to find } \\
\text { somebody who was willing to actually } \\
\text { just sit and listen and genuinely help } \\
\text { me with the process. (ID 100) }\end{array}$ \\
\hline $\begin{array}{l}\text { Learning and honing } \\
\text { new skills }\end{array}$ & $\begin{array}{l}\text { - Organization skills (i.e., } \\
\text { binder) } \\
\text { - Communication skills }\end{array}$ & $\begin{array}{l}\text { On specific strategies learned: } \\
\text { Being organized and being well } \\
\text { prepared before going to meetings at } \\
\text { my son's school. Very well prepared. } \\
\text { (ID 101) }\end{array}$ \\
\hline $\begin{array}{l}\text { Parents' role as } \\
\text { advocates }\end{array}$ & $\begin{array}{l}\text { - Self-confidence } \\
\text { - Personal responsibility } \\
\text { - Stigma reduction and } \\
\text { openness with others }\end{array}$ & $\begin{array}{l}\text { Everyone's always talking about } \\
\text { what's not working... well, what is } \\
\text { working? What was the good quality? } \\
\text { What are the things that are good } \\
\text { about my son, not just what are his } \\
\text { problems. (ID 100) }\end{array}$ \\
\hline
\end{tabular}

Having someone "on your team." A prominent finding of the study was the degree to which participants saw the personalized support offered by the program as the key factor enabling them to successfully negotiate with the schools. All parents communicated that the PIPE program representative offered support, guidance, and encouragement in a manner that helped validate parents' feelings about what their child 
was experiencing and how the school was reacting. When asked about the main strengths of the program, one parent said, "The support, most definitely. Being able to speak to someone that actually understands where you're coming from" (ID 107); and another said, "It was just a huge relief to find somebody who was willing to actually just sit and listen and genuinely help me with the process" (ID 100). In a matter-of-fact way, one parent stated the strengths of the program as being "No judgement. Just listening. Understanding. Empathy." (ID 104). This unconditional support was particularly meaningful for families who felt the school had prematurely labelled their child as having a mental health problem without receiving a proper assessment. One parent expressed the view that "When you are a parent, as soon as you hear that, and especially from someone who doesn't have a medical background to make that kind of diagnosis,... the way it was presented to me was offensive" (ID 105). This parent felt that because the program representative was herself a mother, she could relate to these feelings and validate that they were real. Such personalized conversations helped parents feel that they "weren't going crazy in the way that they felt" (ID 107) and gave them the opportunity to bounce ideas off another parent.

Most parents chose to have the program representative attend a school meeting alongside them and found this to be beneficial for several reasons. When discussing her experience at a school meeting, one parent explained:

She reminded me of points that I had forgotten to mention. She just kind of provided the extra support for me as a parent, and her just being there helped a lot. She did raise some of her own questions if she didn't understand something, and I found that helped having an outsider's kind of opinion. (ID 102)

Parents commented on how the program representative's willingness, openness, and availability to attend the school meetings meant a great deal to them; and one parent noted that the representative was the primary reason behind her feeling satisfied at the end of the meeting. Parents felt that having the representative there helped them feel like it wasn't "them versus the school" (ID 106) and gave them peace of mind to know that they wouldn't miss presenting an important fact or idea. For instance, one parent said, "I did all the talking, but I had someone there who I could look at and refer to if I missed anything" (ID 107).

Finally, parents received guidance from the PIPE program in the form of resources (e.g., books about anxiety) and knowledge about community-based organizations. Parents appreciated that the program representative "went out of her way" to research and obtain resources specific to their situation. On this topic, one parent talked about how when dealing with mental health, finding that helping hand to guide you onto the right path isn't always easy. She continued, "Even though [mental health promotion] is on TV, [help] is so hard to find" (ID 100).

Parents talked in detail about the knowledge and resources they obtained through the program; two of them credited PIPE for getting their child into community-based programming. In one parent's eyes, having the representative at the meeting made the school take the situation more seriously and ultimately led to the child receiving a clinical assessment from a school psychologist. 
Learning and honing new skills. Study findings suggest that it is important to foster organization and communication skills with parents so that they may feel equipped to move forward in their dealings with the school on their own. All eight parents referenced the binder that was put together for them detailing all their child's school records as well as blank pre-meeting worksheets to be filled out. Not only did parents learn how to use the binder effectively, they talked about the importance of "being organized and being very well prepared before going to meetings" (ID 101). Meeting with the program representative to review the binder prior to a school meeting was instrumental in increasing parents' confidence as equal members of the school team:

Everything was just put in order so that we can add to it over time as well as just go back and refer to it by section at any moment. It has worksheets that I find very helpful because it gives you a good way of preparing for a meeting. You know these things can get very emotional and this is a good way of focusing on the facts. I like the way it is set up with the fact that I have all the report cards in there and all the notes the teachers would have left in his Ontario Student Record.... I just find that it really helped us organize things in a way that you don't necessarily think of yourself or take the time to do yourself. (ID 107)

Two features of the binders appeared to be most valuable; the pre-meeting worksheets and the ability to reference and record information at any given time. As one parent explained, "[The program representative] made me sheets for meetings so that before I went in, I would know what three questions I wanted to ask and what I wanted to get out of the meetings" (ID 102). Others discussed the importance of writing down the details of the meeting such as attendees, contact information, and a comprehensive outline of what was discussed to ensure that "everyone has a clear picture of what has happened, what is supposed to happen, and what we agreed to" (ID 107). Parents noted their continued use of the binder in other areas such as medical appointments and psychiatric assessments, even referring to the binder as a "lifeline." As one parent said of an upcoming meeting with a teacher, "I found myself writing a worksheet at home and noting what I want from her" (ID 101).

Parents also gained important communication skills and were given the opportunity to practise these skills through role-play activities with the program representative. Roleplay is an active learning technique that has been found to be effective in teaching communication skills across several disciplines, including education (Chen, Muthitacharoen, \& Frolick, 2003). This gave parents the opportunity to think about their intentions for the meeting; for example, "Why are we having the meeting? Why is it important? What is important for me to say?" (ID 100). Parents learned the importance of remaining objective, calm, and focused on the child during meetings. Some of the families had a tarnished relationship with the school before enrolling in the PIPE program; one parent mentioned learning the importance of "not playing the blame game" (ID 102) with the school. Parents commonly referred to "keeping the emotion out of it and sticking to the facts" (ID 103). One parent discussed learning the significance of word choice and of considering "the lingo" that the school personnel use. Parents gained the ability to take their time and ask for clarification wherever necessary:

People always say, "Do you have any other questions?" How often do we say no? But you actually do have questions. So, you know what, I'm just going to take a minute and look this over and then I'll let you know. (ID 100) 
Parents' role as advocates. A third salient theme that emerged from the data centred on parents becoming stronger advocates for their children. For example, one parent realized that she holds maximum knowledge about her child's situation:

I feel very confident, like I actually have something to say. Teachers and principals change rapidly these days, so they don't know the history, they don't have five years' worth of knowledge. They only know what's happening now, so it's good to be able to reference things quickly and say, "Nope, we tried this, we've done this." It's really valuable. (ID 100)

This finding echoes previous qualitative research, which found that above all, parents want professionals to understand that they are the experts on their child (MacLeod, Causton, Radel, \& Radel, 2017). Parents wanted to be taken seriously and to ensure that they were being heard (MacLeod et al., 2017).

Many parents felt that with the support of the program, they gained the confidence to walk into the school and ask for what they need (e.g., school records) and to participate in school meetings in a way that is respectful, efficient, and focuses on what is best for the child. The program empowered parents to come forward with what their child was experiencing; many of them stated that they continue to ensure new teachers and principals are aware that their child needs "a little extra help" (ID 104). Not only did parents gain the self-assurance to go into meetings on their own, some felt that their improved sense of self-efficacy greatly reduced their overall stress levels:

I gained confidence. Confidence that I would go into meetings on my own and get what I need across to them in a way that everyone can understand me. That's really helped, especially with my stress levels. I have [multiple] children and they're all high needs, so it's helped a lot when I can just go in and tell them what I need. And they understand me as opposed to me having to repeat myself constantly. (ID 102)

Results also highlighted the importance of taking the time to learn about their child's condition, the school's policies and procedures, and the resources available in the community. Parents commonly referenced learning that they do not need to take what the school says as fact (e.g., if the school believes a child has ADHD), and that they should always get a second opinion from a health-care professional. This realization was met with a new sense of power and confidence for one parent who had a long-standing dispute with her child's school:

I think parents should know that they have a lot more power than they think they have, and they are not up against this giant beast of a school board or a bunch of doctors, they are equal in this fight. They're the parents, and they are the best advocate, and they shouldn't just accept whatever is being said, they should question it. You should get second opinions.

You should go to doctors. You should read about it. You should get a book. (ID 100)

For several parents, being an advocate meant that "you don't have to do whatever is suggested by someone else" (ID 100) and that every family has their own path to a solution. This was often linked to conversations about stigma and how being an advocate meant "not letting stigma get in the way" (ID 105). For one parent who reported feeling stressed and offended upon hearing the school's concerns, the program helped her access resources to learn about different mental health challenges; and ultimately, she was able to advocate for the type of intervention her child needed. Another parent felt that the program gave her an "awareness" of her child's mental health, and she noticed being able 
to talk more openly because the program representative "removed the stigma attached to it" (ID 104). Parents felt that part of being an advocate was remembering to focus on the child's strengths rather than just the weaknesses. As one parent noted, "Everyone's always talking about what's not working ... well, what is working? What was the good quality? What are the things that are good about my son, not just what are his problems" (ID 100). In previous qualitative research, parents stressed the importance of focusing on the whole child rather than the child's deficits, stating that "their child is so much more than a file" (MacLeod et al., 2017).

In addition to their role within the education system, parents felt they became stronger advocates within their social circles. As one parent explained:

At first, I was able to talk to [the program representative], and then I was able to talk to friends and family. I went further into the community and let our friends know that if we went to a party and my son didn't want to be there, to understand that it's not their fault and he's not at fault either, it's just something that he's going through. (ID 104)

Many parents talked about sharing the PIPE program with friends and family members who were experiencing hardships, sharing with them that the program is "unbelievably helpful, and you will feel validated and confident, and you will make a connection" (ID 100). Since completing the program, parents have encouraged others to utilize this channel to accessing schools and school boards and have enthusiastically shared their knowledge and skills with friends, family, and co-workers.

\section{Discussion}

The file review revealed that families were experiencing a range of issues both at school and at home. Most commonly, parents were experiencing a short-term disagreement with the school around their child's needs. Indeed, research has identified discrepancies between parent and school perspectives as a key factor that can lead to new or escalated conflict (Lasater, 2016). Many parents in the current study reported a poor relationship with the child's current teacher, which is of concern given that recent qualitative research has shown that some students expressed feeling they need to choose sides between their parents and teacher (Lasater, 2016). Results from Lasater (2016) found that teachers and parents felt that conflicts were often left unresolved, and teachers commonly described parents as either "demanding" or "disengaged" in meetings. Parents reported responding out of fear, worry, stress, or frustration (Lasater, 2016), further highlighting the need for a program such as PIPE in our education system.

The theme having someone "on your team" describes the perceived impact of nonjudgemental support and validation on parents' ability to work with the school. According to parents, they felt a sense of relief to find someone willing to sit and listen to their perspective without rebutting or invalidating their feelings. Parents felt they could relate to the program representative because she herself was a parent. Their ability to relate to another parent echoes findings from a qualitative study on the influence of parent social networks on parental involvement with the school (Curry \& Holter, 2015), which found that having relationships or discussions with other parents are important resources for parents' self-efficacy and motivation, particularly for parents experiencing poverty. Despite the program representative maintaining a professional relationship and 
clear boundaries with clients, her willingness to share her time with them resonated deeply. Parents' strong appreciation for the representative's time could be explained by their feeling frustrated and overwhelmed with the school prior to PIPE (Zeitlin \& Curcic, 2014) and their being relieved and hopeful to feel heard. In fact, when asked about any negative aspects of PIPE, the single response was that parents wish it was better known within their community.

Having the representative attend a school meeting gave parents peace of mind knowing that if they forgot an important point, someone would be there to remind them. By simply walking into a meeting prepared and with a professional by their side, parents felt they had already regained some power, which then encouraged them to stay calm and on task during the meeting. In a recent qualitative study exploring parents' views about how educators could help make the IEP process more collaborative, many parents felt that they needed help to establish trust and rebalance power between them and school personnel (MacLeod et al., 2017). Parents wanted professionals to take the time to inform them about their rights as parents and walk them through the plan (MacLeod et al., 2017). Based on the current findings, the PIPE program addressed these concerns and gave parents the tools to continue to develop an effective partnership with the school.

The theme learning and honing new skills represents two major skills that are fundamental to the PIPE program, communication and organization. Previous research suggests that the way some parents approach the school (e.g., aggressively or passively) may be the result of a lack of knowledge or skills to effectively communicate their needs (Lasater, 2016). Although parents' intentions are to support their child, these situations are often highly emotional, and poor communication can lead to a further breakdown of the school-family partnership (Lasater, 2016). The PIPE program helped parents communicate more effectively by reminding them of the importance of staying calm and reporting their prepared notes in a fact-based and clear manner.

The binder given to each parent was a central takeaway from the PIPE program. Parents learned to think about and record their intentions for the meeting prior to the date, take detailed notes throughout the meeting, and document any decisions made. These skills helped parents feel more confident in ensuing meetings because they had the ability to quickly reference previous records. This sentiment was echoed in a previous study on parents' experiences with the IEP process, in which parents underscored the importance of pre-planning for an IEP meeting (MacLeod et al., 2017). They described the experience of arriving at a school meeting without prior planning as "scary" and "inefficient" and wanted the opportunity to review the IEP in advance of the meeting (Macleod et al., 2017). The PIPE program gives parents the tools to prepare for a meeting in a systematic way (i.e., with the pre-meeting worksheet).

Research on the Hoover-Dempsey and Sandler model (Hoover-Dempsey et al., 2005) has shown that parents' perceptions of their knowledge, skills, time, and energy regarding their involvement with the school predicts their actual involvement (Green et al., 2007). The activities (e.g., role play) and skills incorporated into the PIPE program may have increased parents' perceptions of their competence in this area and could partially explain these findings. 
The theme parents' role as advocates describes parents' perceptions of becoming stronger, more effective advocates for their children. Based on the results of a qualitative study on the experiences of parents and teachers who disagree about a student's needs, teachers felt that parents were trying to be advocates but didn't know how to do so constructively (Lasater, 2016). The author concluded that professional development opportunities for teachers as well as parent advocacy training are needed for schools and families to form partnerships and resolve problems in a way that benefits the child. Without guidance, less involved parents may become merely receivers of information, whereas highly involved parents may become demanding and less willing to compromise (Lasater, 2016). Findings from the current study reveal that parents felt the PIPE program not only improved their confidence during school meetings but encouraged them to seek out school and community resources and to ensure that each of their child's teachers was aware of current challenges and strategies that have worked in the past. This sense of personal responsibility to be frank and open about what their child was experiencing helped parents reflect on their personal stigmas surrounding mental health; and in some cases, parents were able to initiate dialogue with friends and family members about their present situation.

The Hoover-Dempsey and Sandler model outlines that parents must believe that they have an important role as a parent and that they can make positive contributions as a member of the school team (Hoover-Dempsey et al., 2005). Parents with high selfefficacy in this regard believe they can learn information such as that found in an IEP, communicate effectively, and work together to promote their child's school success (Hoover-Dempsey et al., 2005). Study findings suggest that the PIPE program influenced parents' motivation to be involved and gave them a strong sense of confidence as important members of the team.

\section{Limitations and Future Research}

The use of semi-structured interviews was chosen to gather in-depth information on parents' individual experiences with the program; however, each interview was unique, and therefore they cannot be directly compared. The program is relatively new and is currently being piloted with only one facilitator, so sample size was restricted to the number of existing alumni families. Limited demographic information was provided about the participants, and all parent participants were female. As previously noted, a systematic intake form had not been developed at the time when these families were involved with PIPE. The current version of the program includes an intake form, and field notes are taken in a consistent, logical manner. Given the qualitative nature of this work, study findings are not generalizable. Future research should include a larger sample size and should incorporate quantitative measures on outcome variables such as parental role construction, motivation, knowledge, and skills. As the program expands and additional facilitators are trained, it will be important to conduct further research to determine whether findings are explained in part by the characteristics of the facilitator. 


\section{Conclusions}

Parental involvement with the IEP process is required by legislation in Ontario (Ontario Ministry of Education, 2004, p. 13), and there is an established link between such involvement and positive outcomes for students (Castro et al., 2015). Unfortunately, strained relationships between families and schools are common, and parents are often left feeling frustrated and overlooked (MacLeod et al., 2017). This paper has given voice to parents who have been through a novel communications intervention for families struggling to communicate with the school around the mental health needs of their child. Results generated further knowledge on the ways in which parental role construction influences school involvement and illustrated the importance of encouraging self-efficacy and confidence in parents. The PIPE program objectives align closely with previous literature on parents' views on how to make the IEP process more meaningful (MacLeod et al., 2017). From participating in the PIPE program, parents reported feeling satisfied with the support they received and feeling that their goals were met. Parents left the program feeling empowered to advocate for their child at school and in the community. Overall, study findings suggest that participation in the program gave parents a "second wind" and a new or renewed sense of confidence and hope. Parents gained skills for effective communication with the school and felt prepared to continue independently as positive advocates for their children.

\section{References}

Anfara Jr., V. A., \& Mertens, S. B. (2008). Varieties of parent involvement in schooling. Middle School Journal, 39(3), 58-64.

Auerbach, S. (2007). From moral supporters to struggling advocates: Reconceptualizing parent roles in education through the experience of working-class families of color. Urban Education, $42(3), 250-283$.

Azad, G. F., Marcus, S. C., Sheridan, S. M., \& Mandell, D. S. (2018). Partners in school: An innovative parent-teacher consultation model for children with autism spectrum disorder. Journal of Educational and Psychological Consultation, 28(4), 460-486.

Burke, M. M., \& Goldman, S. E. (2015). Identifying the associated factors of mediation and due process in families of students with autism spectrum disorder. Journal of Autism and Developmental Disorders, 45(5), 1345-1353.

Castro, M., Expósito-Casas, E., López-Martín, E., Lizasoain, L., Navarro-Asencio, E., \& Gaviria, J. L. (2015). Parental involvement on student academic achievement: A meta-analysis. Educational Research Review, 14, 33-46.

Chen, L. D., Muthitacharoen, A., \& Frolick, M. N. (2003). Investigating the use of role play training to improve the communication skills of IS professionals: Some empirical evidence. Journal of Computer Information Systems, 43(3), 67-74.

Chrispeels, J. H., \& Rivero, E. (2001). Engaging Latino families for student success: How parent education can reshape parents' sense of place in the education of their children. Peabody Journal of Education, 76(2), 119-169.

Curry, K. A., \& Holter, A. (2019). The influence of parent social networks on parent perceptions and motivation for involvement. Urban Education, 54(4), 535-563. doi:10.1177/0042085915623334

Epstein, J. L., \& Sheldon, S. B. (2002). Present and accounted for: Improving student attendance through family and community involvement. The Journal of Educational Research, 95(5), 308-318. 
Erlingsson, C., \& Brysiewicz, P. (2017). A hands-on guide to doing content analysis. African Journal of Emergency Medicine, 7(3), 93-99.

Fish, W. W. (2008). The IEP meeting: Perceptions of parents of students who receive special education services. Preventing School Failure: Alternative Education for Children and Youth, $53(1), 8-14$.

Goldman, S. E., \& Burke, M. M. (2017). The effectiveness of interventions to increase parent involvement in special education: A systematic literature review and meta-analysis. Exceptionality, 25(2), 97-115.

Gonzalez, L. M., Borders, L. D., Hines, E. M., Villalba, J. A., \& Henderson, A. (2013). Parental involvement in children's education: Considerations for school counselors working with Latino immigrant families. Professional School Counseling, 16(3). doi:10.1177/2156759X1701600303

Green, C. L., Walker, J. M., Hoover-Dempsey, K. V., \& Sandler, H. M. (2007). Parents' motivations for involvement in children's education: An empirical test of a theoretical model of parental involvement. Journal of Educational Psychology, 99(3), 532-544.

Hirsch, S. A. (2004). Impact of parent education on participation and satisfaction in multidisciplinary meetings for specific learning disabilities (Doctoral dissertation). Oklahoma State University.

Hoover-Dempsey, K. V., Walker, J. M., Sandler, H. M., Whetsel, D., Green, C. L., Wilkins, A. S., \& Closson, K. (2005). Why do parents become involved? Research findings and implications. The Elementary School Journal, 106(2), 105-130.

Jarmuz-Smith, S. (2011). Parent involvement in education. National Association of School Psychologists Communique, 39(8), 44-45.

Jeynes, W. H. (2005). A meta-analysis of the relation of parental involvement to urban elementary school student academic achievement. Urban Education, 40(3), 237-269.

Jivanjee, P., Kruzich, J. M., Friesen, B. J., \& Robinson, A. (2007). Family perceptions of participation in educational planning for children receiving mental health services. School Social Work Journal, 32, 75-92.

Jones, B. A., \& Gansle, K. A. (2010). The effects of a mini-conference, socioeconomic status, and parent education on perceived and actual parent participation in individual education program meetings. Research in the Schools, 17(2), 23-38.

Louise Barriball, K., \& While, A. (1994). Collecting data using a semi-structured interview: A discussion paper. Journal of Advanced Nursing, 19(2), 328-335.

Ma, X., Shen, J., Krenn, H. Y., Hu, S., \& Yuan, J. (2016). A meta-analysis of the relationship between learning outcomes and parental involvement during early childhood education and early elementary education. Educational Psychology Review, 28(4), 771-801.

MacLeod, K., Causton, J. N., Radel, M., \& Radel, P. (2017). Rethinking the Individualized Education Plan process: Voices from the other side of the table. Disability \& Society, 32(3), 381-400.

Martin, J. E., Van Dycke, J. L., Greene, B. A., Gardner, J. E., Christensen, W. R., Woods, L. L., \& Lovett, D. L. (2006). Direct observation of teacher-directed IEP meetings: Establishing the need for student IEP meeting instruction. Exceptional Children, 72, 187-200.

Mautone, J. A., Marcelle, E., Tresco, K. E., \& Power, T. J. (2015). Assessing the quality of parentteacher relationships for students with ADHD. Psychology in the Schools, 52(2), 196-207.

Murray, M. M., Ackerman-Spain, K., Williams, E. U., \& Ryley, A. T. (2011). Knowledge is power: Empowering the autism community through parent-professional training. School Community Journal, 21(1), 19-36. 
Ontario Ministry of Education. (2017, November 9). The Individual Education Plan process [Web page]. Retrieved from http://www.edu.gov.on.ca/eng/general/elemsec/speced/individu.html

Ontario Ministry of Education. (2004). The Individualized Education Plan (IEP): A resource guide. Toronto, ON: Queen's Printer for Ontario. Retrieved from http://www.edu.gov.on.ca/eng /general/elemsec/speced/guide/resource/iepresguid.pdf

Patton, M. Q. (2002). Two decades of developments in qualitative inquiry: A personal, experiential perspective. Qualitative Social Work, 1(3), 261-283.

Sheridan, S. M., Eagle, J. W., \& Doll, B. (2006). An examination of the efficacy of conjoint behavioral consultation with diverse clients. School Psychology Quarterly, 21(4), 396-417.

Sheridan, S. M., Kratochwill, T. R., \& Bergan, J. R. (1996). Models for working with parents. In Conjoint behavioral consultation: A procedural manual (pp. 19-32). Boston, MA: Springer.

Zeitlin, V. M., \& Curcic, S. (2014). Parental voices on individualized education programs: 'Oh, IEP meeting tomorrow? Rum tonight!'. Disability \& Society, 29(3), 373-387.

\section{Authors' Note}

Correspondence concerning this article should be addressed to Courtney Cadieux, Centre for School Mental Health, Western University, John George Althouse Faculty of Education Building, Rm. 1154, London, ON, N6G 1G7, Canada. Email: ccadieu2@uwo.ca 